Burges Watson. I. P. (1990) "Is violence a contagious disease?" The social implications of post-traumatic stress disorder. Irish Journal of Psychological Medicine. 7, 47-52.

GUNTRIP, H. (1971) Psychoanalytic Therapy and the Self. New York: Basic Books.

Ulman, R. B. \& Brothers, D. (1988) The Shattered Self. Hillsdale NJ: The Analytic Press.

Vfterans' Administration (1985) The Physician's Guide for Disability Evaluation and Examination. Washington DC Department of Medicine and Surgery, Veterans'Administration.

I. P. Burges Watson

308 Murray Street

Hobart 7000

Tasmania

Access to Health Records Act, 1990

SIR: I feel it is important to draw colleagues attention to the likely effects of this Act.

From 1 November 1991, patients will have a statutory right of access to their health records. From 1987, this has applied to computer health records (Data Protection Act Subject Access Modification (Health) Order, 1987), but the new legislation relates also to manually written health records.

The only information which may not be revealed is that which the record holder believes likely to cause serious harm to the physical or mental health of the patient or any other person. The record holder must not reveal information related to or provided by an individual, other than the patient, who could be identified by that information, unless that person consents. (This restriction does not apply if a person so identified is a health professional who has cared for the patient.)

This is important for child psychiatrists because:

(a) The application can be made by a child (under the age of 16) if the holder is convinced the child is capable of understanding the application. It could also be made by a parent (or person having parental responsibility) but only with the child's consent (if capable). If the child is incapable of understanding, but access is in its best interest, it can be given.

(b) Confidentiality - any information given by a child in the expectation that it would be kept confidential cannot be revealed.

(c) The Act is unclear about situations where the parent's and the child's interests do not coincide, i.e. where there is suspicion or certainty of child abuse.

It is important for all psychiatrists because the record holder is the person who decides whether or not to reveal information, on the grounds that it is or is not likely to cause serious harm to the physical or mental health of the patient or any other persons. If the record is held by a health service body the 'appropriate health professional' must be consulted. If the holder of the record is the General Practitioner (GP), he or she can give access but need not consult with the specialist. Hence, any psychiatrist writing to a GP and conveying information which he or she feels might be damaging to the patient to know might be well advised to state this in the letter. The decision about potential harm, however, rests with the record holder - the GP. It is important for there to be liaison between psychiatrists and GPs before extracts from psychiatric records are released.

The record holder may reveal information given by a health professional without the consent of that person. If the information relates to, or is provided by, another individual, not a health professional, it may not be revealed without the individual's consent. This will mainly apply to two groups-patient's relatives, and other non-health professionals such as social workers or teachers.

It is not essential to produce all the records (any potentially harmful information may be kept in a separate section) but the records must be kept in a way that will facilitate access if requested. Should we be copying the Social Services system of a main file which is open, and a smaller confidential section containing potentially harmful, confidential and third party information?

The BMA's advice is to avoid expressing views about the patient's behaviour or temperament. This is extremely difficult for psychiatrists to follow. Correct factual information which can be verified by the patient would be valuable, as would be a clear and agreed treatment plan. Case notes may in the future evolve without a description, or reflective musing, and with an inhibited kind of formulation, differential diagnosis, and prognosis. This will have an adverse effect on patient care.

Surrey Child and Family Consultation Service

A. M. Gaitonde Health Centre

10 Gresham Road

Oxted, Surrey RH8 OBQ

\section{Chloroquine-induced mania}

SIR: Attention has been drawn in these pages to malaria presenting as depression (Arun Prakash \& Stein, Journal, April 1990, 156, 594-595). With increasing distant foreign travel, clinicians should be aware of the psychiatric complications not only of the disease but also the drugs used in prevention and treatment. A toxic confusional state with psychosis has been reported as a rare adverse effect of chloroquine (Brookes 1966; Rockwell, 1968; Good \& 